\title{
An Experiment in Catalog Reform
}

A CARD CATAlog is like Mark Twain's weather, about which everybody talks, but does nothing. These are the familiar reasons why people complain about the catalog: it is too difficult to use; it is too big; it does not analyze enough; it appears to hide information instead of exhibiting it clearly. The ones to do something about the situation are obviously the catalogers. However, they seldom have the time or the staff for long-term projects and are forced to hope that their running repairs on the catalog will dry up the complaints against it. In addition to being a forlorn hope, this philosophy is plainly dangerous. It is virtually an invitation for some superior agency (chief librarian, academic council, or library board) to issue a ukase that hardly distinguishes between cause or effect and which may worsen a situation it intends to better.

To avoid this, it is the duty of the catalogers to deal with catalog criticism themselves, since the catalog is their product and their ultimate responsibility. It is merely guided, and in no way governed, by the opinions of public service librarians. Catalogers who will not meet changing requirements of the catalog user confirm the popular conception of catalogers as reactionary and unhelpful, more interested in dead detail than in living needs.

When it became clear that the catalog of the Air University Library was no longer satisfying reader needs, a series of phased reforms were begun. These frankly experimental solutions are the subject of this paper.

Mr. Field is chief, catalog branch, Air University Library, Maxwell Air Force Base, Alabama.

\section{BACKGROUND}

The catalog of the Air University Library was started when the library was established, early in 1946. This was a dictionary catalog, incorporating part of the catalog of the Air Corps Tactical School, forerunner of the university. In December, 1946, the catalog was divided into an author-title catalog and a subject catalog.

It was felt that a central subjectauthority unit would be a useful adjunct to the catalog branch. This unit was active from 1947 until 1952. The subjectauthority unit had the task of establishing new subject entries and coordinating those used for books, which were catalogued with the Dewey classification using Library of Congress subject headings, with those used for report literature, which were classified by a modified accession-number system usually with no applicable Library of Congress headings.

So that a new and inexperienced clerical staff might more quickly process the great quantities of materials coming to the catalogers, and so that the catalog in its developmental stage might keep subject mobility, it was decided to use subject guide cards, one for each different subject represented in the catalog, instead of typing subject headings on the catalog cards. See also references were typed on the guide cards.

Liberal use was made of title entry, analytics for series, and subject headings. This is as it should be in the early years of a library, when the collection is small and what is available must be used to the utmost.

The growth of the collection has been phenomenal. The holdings as of May 1 , 1956 , were 245,648 books and bound pe- 
riodicals, exclusive of multiple duplicates, and 527,854 documents. This growth brought with it increasing complaints that the catalog was difficult to use. Such complaints are endemic to a large catalog. It is axiomatic that the complexity of a catalog's entries increase with its size. They indicate that the cata$\log$ is going into another phase of its development, and new plans are in order. Among these are the necessity for making firm basic decisions on the limits of the catalog's function in exhibiting information available in the library, the promotion of such auxiliary aids as bibliographies and vertical files, and the guarantee of their competent upkeep. At this point the chief cataloger stops concerning himself with increasing the cataloged holdings and instead considers more positively what he should not catalog of incoming materials and what materials already cataloged may be withdrawn or have their mode of exhibition condensed.

These were the problems considered in the reform of the catalog. This is the order in which they were attacked: the deletion of title entries; the division of the catalog into an author catalog and a subject-title catalog; the removal of the subject guide cards; the removal of see also references; weeding; special treatment of U. S. entries; and chronological arrangement of heavily represented subjects.

\section{Deletion of Title Entries}

Title listing is the first expendable function of the catalog which comes to mind when the time comes to change the catalog from its medium-size collection service to large collection service. This problem was faced in 1953 by a previous chief cataloger at the Air University when he issued a very sound and carefully worked out memorandum on title deletion, together with a list of over a hundred filing words generally to be deleted as titles. ${ }^{1}$
Title deletion is a hazardous expedient. Based on the assumption that, with certain exceptions, titles beginning with subject headings may be safely deleted, together with certain frequently used title-starters such as How, Introduction, Handbook, and titles that represent literary forms, such as Essays, Poems, Plays, it soon runs into difficulties. How to Build Modern Furniture is quite a different recovery problem from How to Get It from the Government or How to Help Your Husband Get Ahead in His Social and Business Life. There is no assurance that the reference librarian, much less the reader, who discovers the first title under FURNITURE will automatically turn to U. S.-POL. \& GovT.-1945for the second and success and wives for the third.

Nor does the answer lie in omitting from the catalog all title entries that admit of easy subject approach, but including all that do not. Under these circumstances, a reader finding the title How to Get It from the Government but not How to Build Modern Furniture assumes that the latter title is not in the library collection since it is not listed. Of all the unfortunate things readers will choose to remember, the worst is the un-truism: "The catalog lists all the books in the library by author, subject and title."

There is no real solution to the title problem, short of including all or excluding all. Any middle road opens the way to varying interpretations. What was finally done at the Air University Library was to hold fast to the practice of deletion, inserting guide cards throughout the catalog bearing the sometimes deleted word and a warning:

\section{HOW \\ Titles beginning with this word are not generally included in the card catalog. If you do not find your title, look for it under}

1 U. S. Air University. Library. Catalog Branch. "Cataloging and Classification Notes and Decisions 17-53 (Revised) August 14, 1953." Unpublished. 
subject, or ask a librarian to help you.

\section{The Catalog Is Divided Again}

The other thing that was done to make the catalog more useful by giving the reader some clue to omitted titles was to divide the catalog into an author section and a subject-title section.

In libraries where the dictionary arrangement is not used, the most common plan is to arrange the catalog into an author-title section and a subject section. $^{2}$ This arrangement deals neatly with the relatively minor problem of authored and non-authored entries, but assumes that readers will run down the smallest item of information, no matter how carefully it is hidden. This concept has caused the catalog to become increasingly a tool created by catalogers for each other. If it is true, as catalogers so often say, that even reference librarians do not know how to use the catalog, the fault is as much that of the catalogers as of the reference librarians, since, while it is true the latter must know their subject headings to use the catalog, it is also true that the former must arrange it for most efficient use. While both are raucously laying down the qualifications of their game of card-chase, the poor reader has quietly disqualified himself and left the field.

While the reader may give up soon in a dictionary catalog, he has scarcely any chance at all in the author-title and subject catalog. This arrangement ignores two facts. The first is that titles support subjects and not authors, save incidentally. The second point is that readers are as likely to think of titles as of subjects. Anyone who has served a term in a reference department knows that a pertinent title comes to mind at least as often as the sometimes elusive subject assigned to it.

Many distinctive titles are quasi-

${ }^{2}$ V. J. Burch, "Divided Catalog: Duke University Library Catalog Faces the Future," CRL, III (1942), 219-23; A. F. Wood, "California Divides Its Catalog," Library Journal, LXIII (1938), 723-26. subjects in that they embody the subject matter of the book in a vulgate form, often completely different from the official subject entry for it. These quasisubjects constitute a mantrap in a cata$\log$ divided by author and title and by subject. Even the most astute reader runs the danger of assuming that they represent the total holdings of the library in his field of interest. This arrangement of the catalog makes no provision for leading the reader into his subject field, since the cross references from his quasisubject to its catalog form are not in the author-title catalog at all, but in the subject catalog, and the reader may never look there.

The arrangement by author catalog and by subject-title catalog, on the other hand, obviates completely any such culde-sac, since it drives the reader from his quasi-subject to the "official" subject by means of an inescapable cross reference. An example will show this. If a reader interested in the subject of federal aid to education finds a book called Federal Aid for Education in the author-title catalog, he is likely to stop there. In a subject-title catalog, this title would be deleted, as it stands close to the reference FEDERAL AID TO EDUCATION See EDUCATION AND STATE-U. S. However, it would be a most unrealistic cataloger who would delete the title Federal Aid for Education from the author-title catalog, expecting the reader to continue his search in the subject catalog under FEDERAL AID TO EDUCATION and thence to EDUCATION AND STATE-U. S.

To come to the conclusion that the author and subject-title arrangement is the best one for a given situation is one thing. To clear the way for this transformation in a heavily used catalog of 655 trays is another. The first step in the shift was to draw up a list of the title entries to be transferred from the authortitle catalog to the subject-title catalog. These were: all titles, all non-author series, all non-author serials, all title 
analytics. The list gave examples and outlined procedure. Next, a 60-tray unit was added to the catalog to obviate heavy shifting during the change-over, and space was made where the need for it was anticipated. Finally, the task of shifting the catalog cards was done by the readers service librarians. They made time for it in their regular schedules and completed the task in eighteen days. Without the help of the readers service librarians, the task would have been quite impossible.

\section{Subject Guide Cards}

The catalog was now ready for the next phase of change, the removal of the subject guide cards.

No one who has had to set up a library catalog in an institution where considerable growth is expected would question the decision to use guide cards instead of typed-on headings, given the need for speed and faced with the problems that numerous, changing subject headings present. However, the fact remains that the only continuing good of the guide cards is that they require slightly less clerical attention, and, on the good housekeeping side, they appear to keep catalog cards looking cleaner. Everything else is against them.

Subject guide cards complicate the cataloging process by requiring that special measures be taken to make sure they are made or not made, as the need may be. They slow down filing because they hide cards filed above the rod, and cause them to be overlooked by revisers.

Where a run of subject guide cards with the same main subject but with differing subdivisions has only one author card behind each of them, the question arises whether subdivisions of less represented subjects are necessary on guide cards, or, indeed, if they are necessary at all. This latter query is a reasonable one, but disquieting to a cataloger if it comes from the administration. A cataloger is trained to base present practices on future expectations, not to limit them to the present situation. There is future trouble implicit in the use, say, of the undivided heading ICELAND for a handful of books on such separate subjects as COMMERCE, DEFENSES, DESCRIPTION AND TRAVEL, ECONOMIC CONDITIONS, ECONOMIC POLICY, HISTORY, and POLITICS AND GOVERNMENT.

One answer to this problem is to leave subject subdivisions off guide cards, in the hope that readers will mine them out of the tracings at the bottom of the cards. However, the visibility hazards occasioned by this solution lead only to gross misfiling and reader dissatisfaction.

Intended to make for clarity and order in the catalog, subject guide cards tend rather to present a busy, cluttered appearance that dismays the reader rather than aiding him. Furthermore, their saving in clerical help does not outweigh their nuisance value, since cards must go into typewriters for call numbers in any case, and the subject heading can then be easily added. To revise typing of headings is no time-consuming task if clerical personnel are basically able.

The mobility advantage of the guide cards decreases as catalogers' knowledge of the special subject fields in which they are working matures, and as necessity teaches the chief cataloger restraint. Since he does not have the staff the L. C. Joneses have, he must curb his desire to keep up with them.

The worst feature of the guide cards is their fiendish fertility. This is demonstrated by the following tables:

Subject Catalog Status on 30th September 1954

Card trays in subject area ...... 360

Number of subject cards .......243,100

Number of guide cards . . . . . . 43,000

Breakdown of a Typical Subject Catalog Drawer on 30th September 1954

Cards in tray $\ldots \ldots \ldots \ldots \ldots \ldots \ldots \ldots 6 . \ldots \ldots \ldots$

Number of guide cards ..........275

Number of subject guide cards

controlling less than 3 cards .......180

Number of see reference cards ....... 31 
Whether one looks at the lesser total figure and says that every sixth card in the subject area is a guide card, or at the larger sample figure and says that every third card is a guide card, one has an uncomfortable feeling that the guide cards will eventually take over the cata$\log$. There is only small comfort in the thought that the number of additional new subjects will decrease as the catalog grows. Actually, the average monthly addition of new subject guides over the period 1946-1954 was 398 per month, and the average monthly addition of new subject guides in 1954 was 281.

\section{The Guide Cards Go}

Plainly, the next project was to remove the guide cards. However, the problems involved in this were not simple ones: If the guide cards were removed, who would be found to type on a quarter of a million subject headings? A typist can type 95 headings an hour, so the task would require as a very minimum 65 work weeks of a typist's time. Obviously a method other than typing was required. Hand-set rubber stamps were finally chosen as the solution.

As the first step, it was decided that any subject represented 25 or more times in the catalog should have its subject stamped on, and any subject represented less than 25 times should have its subject typed on. The catalog branch prepared a list of subject headings represented 25 or more times in the catalog, and on this list starred those represented 100 or more times, for consideration for chronological arrangement. This list contained 1,565 entries in all. The director's office staff set up the stamps and the readers service librarians again helped, this time by doing the stamping. Stamping was completed in two months' time. The typists began typing cards for the less represented subjects concurrently with the stamping operation, so that the catalog might present its changed appearance as soon as possible. While no one would say the catalog now presents the highly groomed appearance given by tray after tray of meticulously typed headings, it can be reported that stamping has reduced by over one half the time required to get rid of the guide cards.

The question may arise why an outside service should work on a project that would appear to be the responsibility of an inside service. One cannot think the readers service people welcomed this task-who would, being in his right mind?-but they did need to know what was taking place in the catalog so that they could use it most efficiently while it was undergoing change. It was important, too, that they should see how the old construction of the catalog was impairing its present usefulness. Needless to say, they turned up some cataloging howlers that needed attention, and throughout the project they asked pointed and thoughtful questions concerning the value of present practices.

Credit for the accomplishment of this task is due the readers service librarians, but even greater credit is due the catalogers who for a decade worked to create so basically sound a fabric that it could withstand being rent apart and reorganized. It is not every catalog that is worth reorganizing. Cases are known to exist in which a completely new start is the best solution to the problem. Thanks to the work of the present and former staff, the catalog has assumed its new look, with an average of six guide cards in trays which used to hold as many as 275 , and redundant title entries have disappeared.

\section{The See Also References}

Under the old guide card plan, see also references were typed on the subject guide cards. As cards were stamped or typed during the catalog's reformation all guide cards were turned over to the catalog branch, where those with see also's were retained, and those with no see also's were destroyed. 
Removed from the catalog were 4,587 guide cards with see also references, and 32,750 "plain" guide cards, exclusive of those in the U. S. subject area. Under these guide cards were 105,570 subject entries. The decision to be made concerning these guide cards is whether they should be returned to the catalog wholly, in part, or not at all. The final decision depends on the opinions voiced by the readers service librarians. So far they have said nothing, one way or the other. ${ }^{3}$

If this silence continues, it is likely that only those see also references that refer from subjects originated locally will be returned to the catalog. See also's originated by the Library of Congress would under this plan be removed permanently and the Library of Congress printed subject lists be placed near the catalog for perusal by those interested. It is known that the maintenance of see also's from ABBOTs see also CHRISTIAN BIOGRAPHY to ZUNI INDIANS See also PUEBLO INDIANS takes the full time service of one cataloger contributed piecemeal by the whole staff. This is too great a price to pay for the upkeep of Abbots or of Zunis or for what lies in between.

Such changes as these cannot be undertaken without staff-wide publicity. This was done by means of $A$ Manual of Principles on Limited Cataloging for the Air University, issued in its fourth draft form in May, 1956. Drawn up after consultation with the readers service librarians, this manual incorporates their expressed needs and the local catalog practices.

\section{Future Plans}

Other plans for increasing the usefulness of the catalog are still under study. In the probable order of their consideration these are: precataloging selection, the treatment of retrospective materials and the simplification of entry, particularly for U. S. government bodies.

\footnotetext{
${ }^{3}$ This appears to be following the experience of the University of California catalog, which contains selected see also's from main subjects to identical place or language subdivisions, but does not use see also's per se. Instead, the Library of Congress subject headper se. Instead, the Library of Congress subject head
ing lists are made available at the subject catalog.
}

No matter how it is handled, cataloging is a time-consuming process which should be applied only to materials possessing more than temporary value. It is felt that much of the confusing bulk in the catalog will disappear when the catalog stops being the only and inevitable terminus for guidance to acquired materials. Complete plans remain to be made in other methods of disposing of ephemeral material, and among these are the promotion of the use of indexes, vertical files and wastebaskets. It is in the first two that readers and public service librarians should look for current affairs briefs, topical serials and other readyreference materials whose interest is limited in time, and into the last that more gift material can often go.

This does not imply that the library's present acquisitions policies are unsatisfactory. Anyone familiar with these, and with methods by which they are carried out can only have the greatest professional admiration for them. ${ }^{4}$ However, catalogers also have a logical responsibility for participation in selection. When catalogers take this part, their mental attitude is improved, because they need no longer wonder, as they sometimes must, if they are engaged in nonessential work.

There are at present 511 subjects in the catalog represented 100 to 800 times. The approach to cataloged materials would be made easier if retrospective materials were withdrawn, possibly to an historical catalog. Such an operation would be selective, and not a blanket removal by date. The remaining cards, arranged chronologically by imprint, the latest first, would have a form reference to the historical catalog. An advantage of date-arrangement of the remaining cards would be the ease with which subjects could be kept up to date.

It is well known that the U. S. area in any catalog is rough terrain for the com-

\footnotetext{
4 Mary Lofton Simpson, "An Experiment in Acqui-
sitions with the Lamont Library List," $C R L$, XV (1954), 430-33.
}

(Continued on page 430) 
edited, manufactured and distributed to some 5,000 ACRL members last year for a total cost, including headquarters salaries, of $\$ 4,700$.

The key to ACRL's financial picture lies, of course, in the main budget, which includes the net cost of the journal. ACRL began small in number of members and in income, and grew slowly during the first years. It had cash balances of $\$ 8,500$ in 1949 , $\$ 11,500$ in $1950, \$ 14,000$ in 1952 , and a high of $\$ 16,800$ in 1953 . As this balance increased in size it became apparent to the Board of Directors that a broadened program was possible and desirable. ACRL is a service organization and takes no satisfaction in amassing a large bank account. Therefore in the fall of 1953 the ACRL staff was increased from 2.5 to 4 with the expectation that this staff cost would result in severe deficits for several years and might be more than the division could finance indefinitely. The divisional year-end balance decreased to $\$ 13,350$ in $1954, \$ 8,600$ in 1955 and will drop to approximately $\$ 6,800$ in 1956 , according to official May estimates. Of course the ACRL program expanded in many ways other than staff in the past three years. It is a particular satisfaction to report that income will nearly equal expenditure this past year because very large sums have been spent on the Organization Manual and the foundation grants program, which will be self-supporting in 1956/57.

The year now ending is the last during which ACRL will receive support under the ALA formula which has been in operation since 1950. Likewise this is the last year for operation under a divisional budget drawn up by the Board of Directors. During the next few months ACRL will turn over to ALA its current balance of approximately $\$ 6,800$ as well as Monograph assets estimated at $\$ 2,750$.

In short, our current financial picture is sound. Our program as well as our costs were nearly doubled in 1953 , but the division has been able to build its income sufficiently, without any additional or special aid from ALA, to the point of a nearly balanced budget, and to maintain a reserve for emergencies and special projects.-Arthur $T$. Hamlin.

\section{An Experiment in Catalog Reform}

(Continued from page 419)

mon reader. Its complexities are multiplied in a collection that is both government sponsored and heavy with report literature. At present, the U. S. is being removed from all official U. S. corporate entries, and the cards are being refiled under the next word in their heading. For example, u. s. DEPT. OF STATE is being changed to DEPT. OF STATE. An even more drastically direct entry is planned for Air Force headings which will change U. S. AIR FORCE. STRATEGIC AIR COMMAND, for example, to STRATEGIC AIR COMMAND. This treatment is very concisely described by Croxton as "Entry ... by the smallest significant component."5 Entry similar to this has been used successfully for some years in the Air University Periodical Index.
These are the future plans for the catalog. They call for a great deal more thinking as their full implications are not known nor their pitfalls completely explored. A catalog as big as that of the Air University will make too great a noise if it collapses under ill-considered change. With us, the needs of the cata$\log$ as well as those of the public it serves are under continuous scrutiny, and for the rest there is inspiration in the motto of the Air University itself: Proficimus more irretenti. This writer prefers to translate it as: We are of service, not being held fast by rules.

\footnotetext{
5 F. E. Croxton, "Identification of Technical Reports." In The Production and Use of Technical Reports, ed. by Bernard M. Fry and Rev. James J. Kortendick (Washington, D. C.: Catholic University of America Press, 1955), p. 127.
} 